\title{
New directions in sustainability science: promoting integration and cooperation
}

\author{
Joanne Kauffman $\cdot$ Salvatore Arico
}

Published online: 8 August 2014

(C) Springer Japan 2014

Since this journal was launched in 2006 to provide a platform for the pioneers of sustainability science (Komiyama and Takeuchi 2006), the science has matured in the development of theory and methodologies to address the potentially devastating consequences of the present development paradigm. The gains in research, however, do not mean that sustainability science in its present state will fulfill its promise of transformational change (Van der Leeuw et al. 2012). Hurdles remain, including insufficient engagement with stakeholder groups (Wiek et al. 2012), lack of robust communication and entrepreneurial skills on the part of scientists generally (Baron 2010; Brownell et al. 2013), the need for better support (structural and intellectual) within the academy to attract and maintain committed scholars to the field, and enhanced qualitative and quantitative meta-studies to make better use of experiences and evidence emerging from sustainability science research (Wiek et al. 2012). In sum, these challenges are symptomatic of a disconnect between the nascent science and society. If sustainability scientists are going to contribute to transformative change to achieve sustainable development, they must accept roles that go beyond traditional reflective scientist modes and that are outside of their professional comfort zones. It is clear that a higher level of knowledge integration and greater (tighter) cooperation between the generators and users of such knowledge are needed to

\footnotetext{
J. Kauffman $(\bowtie)$

Integrated Research System for Sustainability Science (IR3S),

The University of Tokyo, and Massachusetts Institute of

Technology (retired), Le Clavet, 83670, Fox Amphoux, France

e-mail: Kauffman@alum.mit.edu

S. Arico

Natural Sciences Sector, United Nations Educational, Scientific and Cultural Organisation, 1, rue Mollis, 75011 Paris, France
}

overcome barriers to meeting these challenges. (Frodeman et al. 2010; Wiek et al. 2012; Komiyama 2014).

Recognizing this, sustainability science has called for this special issue to explore the need for and ways to promote greater integration and cooperation in fulfilling the sustainability science mandate. As Kates (2010) points out "the distinctive knowledge created by sustainability science is use-inspired and, at its best, provides solutions to real-world problems encountered for the needs of a sustainability transition", which Wiek et al. (2012) have called "transformational change".

The problems sustainability science is meant to address have not diminished in the twentieth century. The 2014 report of Working Group II of the Intergovernmental Panel on Climate Change (IPCC 2014) is sobering in its predictions, yet hopeful with regard to our capacity to change. The Rio+20 Conference on Sustainable Development similarly agreed that it was possible to overcome the hurdles to sustainable development by the Millennium Development Goals (MDGs) of 2000. In spite of limited progress in meeting those goals (United Nations and Millennium Development Goals Report 2011), delegates to Rio+20 launched an inclusive intergovernmental process to develop a set of sustainable development goals (SDGs), which will converge with the Post-2015 Millennium Development Goals to arrive at one global agenda, with sustainable development at its center. ${ }^{1}$ In this political arena, sustainability science, with its problem-focused and solution-oriented transdisciplinary approach, provides a useful tool, methodology and basis for dealing with interconnected problems and integrating knowledge from all disciplines to develop this new global agenda. But to realize this goal, sustainability science must itself break

\footnotetext{
${ }^{1}$ see, http://sustainabledevelopment.un.org/futurewewant.html.
} 
through formidable barriers of inertia and lack of political will (Van der Leeuw et al. 2012).

Investment in science in most developed countries is predicated upon a (unwritten) social contract between science and society. (Lubchenco 1998) The vast explosion in knowledge since World War II is in large measure due to these investments that carried with them the expectation that a substantial investment in scientific research will result in societal benefits (Ibid., Skolnikoff 1993). For many decades this relationship or "contract" worked to the benefit of both the scientific enterprise and society, as standards of living, health and and security rose in those countries to the point where the 20th century has been called by some as "the golden age of science". As science developed to address specific deficits and needs in society, it became increasingly compartmentalized and specialized, and the distance between human values and science gradually increased. (Komiyama 2014, 17) Moreover, with ever increasing acceleration over the same time period and, especially, in the last 30 years, man's impact on the biosphere has increased dramatically and led to a myriad of profound changes that are occurring faster than they can be interpreted. Today, no ecosystem on Earth is free of pervasive human influence and many scientists believe that the changes are so great that we have entered a new geological age, which they call the Anthropocene (Vitousek et al. 1997; Steffen et al. 2007).

Recognizing that socio-ecological problems and deficits that result from the consequences of these changes (climate change, ecological degradation, biodiversity loss, dramatic changes in landscape, war and entrenched poverty) are not amenable to strict disciplinary approaches has led to many experiments in disciplinary border crossing between the physical and natural sciences and social sciences (Frodeman et al. 2001). There is an active debate and urgency in academia and civil society on methods and approaches to help integrate the vast amounts of knowledge being produced to help make it more relevant to the increasingly complex problems our world faces (Frodeman et al. 2010; Jacobs 2014). ${ }^{2}$ The emergence and development of sustainability science is emblematic of this scientific advancement (Kates 2010 and 2011).

Yet, the question raised in a special issue of Sustainability Science in 2012 on bridging the gap between science and society remains: considering that research and education are valuable but not sufficient contributions to solving sustainability problems, what is a reasonable mission for sustainability science (Wiek et al. 2012)? That issue of the journal focused on the link between science

\footnotetext{
${ }^{2}$ See, also, Klein (1990) on the history of interdisciplinarity which tracks the types of border traffic between disciplines (e.g., multidisciplinarity, crossdisciplinarity and transdisciplinarity) to overcome problems of specialization to better address complex issues.
}

and society in sustainability efforts presenting innovative epistemologies and methodologies for moving forward (from problem-focused to solution-focused research; from searching what to do to determining how to do it; from the power of techno-science to new kinds of hybrid knowledge and practice through extended participatory processes) (Ibid, p3).

By redefining the functions, mandate and scope of scientific inquiry, sustainability science seeks to be responsive to the needs of and values in society while supporting the life-support systems of the planet (Jerneck et al. 2010; Kates et al. 2001; Backstrand 2003; Miller 2012). As that special issue of sustainability science illustrated, new integrated approaches that go beyond interdisciplinary research to incorporate knowledge from outside the academy and ensure the inclusion of indigenous knowledge through broad participatory approaches have been developed and tested (Shiroyama et.al. 2012; Orecchini et al. 2012; Wiek et al. 2012). While promising, challenges remain, particularly with regard to structuring and implementing strong collaborative research processes in which scientists and stakeholders interact throughout the research process.

In response to that issue, sustainability science has organized this special issue to focus on ways in which sustainability scientists are working and can work to achieve a higher level of integration and cooperation that is needed to advance its goals. The special issue stems from a symposium held at the headquarters of the United Nations Education Science and Cultural Organization (UNESCO) titled "Promoting Integration and Cooperation for Sustainability" in September 2013. In her overview article, Kauffman puts the views expressed during the symposium in the context of challenges to sustainability scientists today. The central question put to symposium participants was one that many policy and decision makers as well as scholars struggle with today, ${ }^{3}$ namely: how can we overcome barriers to action that will put societies around the world on a path to a more stable and sustainable future? What emerged in discussions is recognition that the need for action now can only be met through strengthening the science-policy-society interface. Keynote speakers and panelists alike emphasized the stark fact that the consequences of accelerated human impacts on the earth systems are not issues for the future. They are with us now. While recognizing that all sciences (natural, technological and social sciences included) are needed to meet the challenges, this is indisputable; participants acknowledged that problems that stem from the accelerating human impact

\footnotetext{
${ }^{3}$ See the special issue of Sustainability Science, Sustainability science: bridging the gap between science and society. Sustain Sci vol 7, supplement 1, February 2012.
} 
were effectively not being met. Thus, the quest for higher levels of integration to develop new knowledge and to increase cooperation to put such knowledge into action has taken on greater urgency. Three steps that can be taken now emerged from the symposium:

(a) Building societal and ecological resilience;

(b) Increasing collaboration across disciplinary, social and geographical boundaries; and

(c) Enhancing education for sustainable development.

These points are taken up in various ways by the papers in this special issue. The papers are organized into three clusters. The first four articles focus on the history and evolution of sustainability science and take stock of current challenges to strengthening the science-policy-society link; the next two articles consider scientific and institutional barriers to the transdisciplinary approach and means to overcome them; the special issue concludes with two articles that focus on the future. The first of these is an overview article that presents quality criteria for developing visions and visioning in sustainability research and proposes two integrative research project frameworks drawn from complexity theory that illustrate the use of the criteria. The second explores the value of building socialecological resilience through a case study on applying sustainability science to strengthening social-ecological resilience in recovery efforts in NE Japan.

Kajikawa, Tacoa and Yamaguchi revisit the academic landscape of sustainability science that Kajikawa and other colleagues created in 2007 using an analysis of the citation network to provide evidence of the intellectual evolution of sustainability science (see Kajikawa et al. 2007) In the paper for this special issue, the scholars present the results of their research using citation and text (bibliometric) analysis of published articles and applying this to their methodology to develop a profile of sustainability issues addressed by the science. Their results indicate that separated disciplinary-bound research clusters identified in the earlier study are becoming integrated into those studying coupled systems. An encouraging sign emerging from the analysis is evidence of an increase in recent years (from 2007 to 2009) of attention to socioecological systems and a concomitant interest in the social and political/policy components of the issues studied. Moreover, they find that the science is bridging gaps that are left in traditional scientific research, especially with respect to gaps between social, ecological and economic systems, between diverse disciplines, and between the current state and a sustainable future. This increase suggests that sustainability science, as reflected in the literature, is becoming more concerned with the sciencepolicy-society link that is crucial to moving societies forward on the path to sustainable development.
In his critical examination of five transdisciplinary projects in practice, Polk examines why in some cases knowledge co-generated through transdisciplinary approaches does not necessarily result in the ability to influence change in a sustainable direction. This, he finds, is often due to a lack of sufficient attention paid to delivery mechanisms for sustainability research results. In the cases analyzed by Polk, a lack of institutional incentives and support for participation in and follow-up to the transdisciplinary research process weakened the channels to the decision-making process, resulting in some cases in a weak or broken science-policy-society link. Exacerbating such problems is the fact that many sustainability issues transcend spatial, temporal, sectoral and disciplinary boundaries and thus exceed institutional structures, organizations and political mandates. Polk also notes problems in research structures that can hinder the applicability of the results of transdisciplinary research. He cites in particular the lack of an institutional home for practitioners of such research who are not firmly rooted in either the academy or in practice. This, Polk explains, means that in many cases they risk a lack of legitimacy outside of their immediate sphere of other practitioners. This lack of legitimacy also makes it difficult to capture and utilize project results. He points to the need for more materials available to scholars that explain these difficulties and how they have been overcome as well as provide examples of how to carry out different types of transdisciplinary research in a variety of substantive areas.

There are signs, however, at the international level that channels to decision making may be opening up to transdisciplinary research. The case study by Arico illuminates the way the United Nations and in particular UNESCO is working to achieve the higher level of integration and cross-fertilization of disciplines and to increase stakeholder participation in carrying out its mission to scale up (and to speed up) practical solutions to the sustainable development challenge. Taking this challenge seriously at the behest of its member states, the UNESCO secretariat is forging ahead with plans to mainstream sustainability science (integrated science for sustainable development) into its various programs. A salient feature of these efforts, and one that is new to the international policy arena, is an overt effort to seek out and include indigenous and local knowledge and to move away from strictly conventional approaches to conducting research and creating new knowledge. In this context, the Arico paper informs us of ways in which the newly launched Future Earth initiative is challenging the conventional linear model of knowledge production. ${ }^{4}$

\footnotetext{
$\overline{{ }^{4} \text { www.futureearth.com/info. }}$
} 
Building on the accomplishments of existing global environmental change programs, the Future Earth initiative was launched shortly before Rio +20 , as a new 10-year international research program on global sustainability. This program is designed to mobilize scientists from all disciplines and to strengthen partnerships with stakeholders and policymakers for advancing a global transition toward sustainability. At the heart of this initiative is the idea of co-design of research through a higher level of interaction between stakeholders and scientists. As Arico notes, at the United Nations, the practice of science has always entailed the need to solve problems of great complexity, such as ozone depletion, climate change, lack of food security, social instability and ineffective governance. The Future Earth initiative, created by scientists and decision makers, may serve as a model to rapidly advance awareness of and open channels for transdisciplinary research both within and beyond the international arena. One of the aims of the symposium that is the backdrop to this special issue was to foster better collaboration between scientists and the decision-making and policy arena. The Arico paper examines how sustainability science carried out in both academic and policy arenas can be mutually supportive in further elucidating how, proactively, the transdisciplinary approach can enhance the attainment of sustainable development at multiple scales.

In the first article in the cluster on barriers to transdisciplinary research, Schneider presents a conceptual approach to transdisciplinary scenario building for sustainable water governance and analyzes its application in a specific Swiss setting. The approach combines normative, explorative and participatory scenario elements in an iterative process that ensures the input of stakeholder and local knowledge to the scientific process, thus establishing a robust and meaningful dialog between all the actors involved and stimulating mutual learning. Based on her findings, Schneider argues that scenario analyses can be a tool for strategy development for envisioning sustainable futures, i.e., a vision of what the future should be. For the actors to truly engage in the coproduction of knowledge, however, Schneider maintains that both stakeholders and scientists must remain flexible through the process and the project leadership must create conditions of interaction that put both on equal footing in the discussions. Continual collaboration and the iterative process were keys in the application of the scenario approach for overcoming barriers to developing transformative knowledge.

In the second article of this cluster, Wittmayer and Schapke look more closely at the roles of researchers in process-oriented sustainability research in which joint knowledge production is central and researchers actively participate in dialogs for change (Miller 2012). They consider this approach in a historical context going back to action research and transition management rooted in the early 20th century, for example in the work of John Dewey.
The authors of this paper focus on the ways researchers can create spaces for societal learning and identify key issues that researchers must address in doing so: for example, as Schneider observed, issues of ownership, sustainability, power and action. They then distinguish the activities and roles that are connected to addressing each of these issues and define a set of ideal type roles. Using a literature review to develop a framework for analyzing a case of transition management in Carnisse, a neighborhood of Rotterdam, the four ideal type roles they identified and which they suggest can add to future directions in sustainability science include that of:

- The reflective scientist (a largely traditional process facilitator who can facilitate the learning process in transdisciplinary research processes)

- A knowledge broker: one who mediates relevance and tangibility of sustainability to participants in their work on knowledge construction

- A change agent: one who motivates and empowers participants

- The self-reflective scientist who has the ability and skills to examine her own normative orientations.

In the cluster that focuses on the future, two articles draw our attention to different approaches to visioning in sustainability science. The first, by Wiek and Iwaniec, posit that since sustainability science is about transformative change, visioning is a key method. As the authors point out, sustainability visions are "specific types of visions that provide guidance to achieve sustainability and, therefore, adhere to value-laden or normative principles including that of intergenerational equity" (WCED 1987:43). As they note, sustainability criteria can help to avoid visions that violate important values of justice, integrity and viability. The authors review the literature in this domain and synthesize their findings to provide scholars with a tool to enhance sustainability-visioning practices. Ten criteria for sustainability visions are laid out in a triple axis model of a quality vision: normative, constructive and transformational. The authors present design guidelines that include applying a meaningful sequence to visioning methodologies from framing through analyses, revision and recomposition of the vision. They agree with the findings of Schneider that visioning whether through the use of scenarios or other approaches is an iterative procedure that is conducted in participatory setting to create a shared and plausible (one could say implementable) vision.

Finally, Takeuchi et al. explore the significance of the transdisciplinary sustainability science approach to analyze social and ecological restoration in NE Japan following the devastating effects of the 2011 earthquake and tsunami. This case study of the processes for restoration in the Tohoku region argues that building resilience in the affected 
area requires a transformation to sustainable agriculture, forestry and fisheries and describes how the links between satoyama and satoumi, traditional rural territorial and coastal landscapes in Japan, can contribute to this revitalization and to strengthening the relationship between local residents and the landscape in the affected communities. Decision makers at local, regional and national levels need to take a holistic approach based on sustainability science to understand the inter-relationships between these landscapes and ecosystems to develop a robust rebuilding plan for the affected communities. Moreover, this paper suggests that building resilient communities in Japan that demonstrate the strategic benefits of satoyama and satoumi linkages can be a model for strengthening the science-policy-society link and for building resilient rural and urban communities throughout the world.

As the analyses and case studies presented in this special issue of Sustainability Science illustrate, the daunting nature and complexity of sustainability challenges require a new relationship between science and society, one that leads scientists to go beyond ensuring a scientific foundation for policy and decision making based on specialized disciplinary knowledge to participating in the co-production of knowledge for action through transdisciplinary research. This solution-oriented science implies the validity of multiple epistemologies and an emphasis on action and social learning in contrast with abstract cognitive theorizing (Sala et al. 2012; Van Kerkhoff and Lebel 2006; Clark and Dickson 2003). If it is to achieve its aim of producing what Wiek et al. (2012) have identified as transformational knowledge that leads to sustainable transitions, the science that leads to sustainable transitions must necessarily be produced through collaboration among various disciplines and actors within and outside the academy in robust participatory and iterative processes that recognize policies and proposed solutions as experiments and that foster societal as well as scientific learning and advancement.

\section{References}

Backstrand K (2003) Civic science for sustainability: reframing the role of experts, policy-makers and citizens in environmental governance. Global Environ Politics 3(4):24-41

Baron Nancy (2010) Stand up for science. Nature 468:1032-1033

Brownell SE, Price JV, Steinman L (2013) Science communication to the general public: why we need to teach undergraduate and graduate students this skill as part of their formal scientific training. J Undergrad Neurosci Educ 12(1):E6-E10

Clark WC, Dickson NM (2003) Sustainability science: the emerging research program. Proc Natl Acad Sci 100(14):8059-8061

Frodeman R, Klein JT, Mitcham C, Holbrook JB (2010) The oxford handbook of interdisciplinarity. Oxford University Press, Oxford

Frodeman R, Mitcham C, Sacks AB (2001) questioning interdisciplinarity. Sci Tech Soc Newsletter 127:1-5
IPCC (2014) Summary for policymakers. In: Field CB, Barros VR, Dokken DJ, Mach KJ, Mastrandrea MD, Bilir TE, Chatterjee M, Ebi KL, Estrada YO, Genova RC, Girma B, Kissel ES, Levy AN, MacCracken S, Mastrandrea PR, and White LL (eds.) Climate Change 2014: Impacts, Adaptation, and Vulnerability. Part A: Global and Sectoral Aspects. Contribution of Working Group II to the Fifth Assessment Report of the Intergovernmental Panel on Climate Change. Cambridge University Press, Cambridge, United Kingdom and New York, pp 1-32. Available online at: http://ipcc-wg2.gov/AR5/images/uploads/WG2AR5_SPM_ FINAL.pdf

Jacobs, Jerry A (2014) In defense of disciplines: interdisciplinarity and specialization in the Research University. University of Chicago Press, Chicago

Jerneck A, Olsson L, Ness B, Anderberg S, Baier M, Clark E, Hickler T, Hornborg A, Kronsell A, Lovbrand E, Persson J (2010) Structuring sustainability science. Sustain Sci 6:69-82. doi:10. 1007/s11625-010-0117-x

Kajikawa Y, Ohno J, Takeda Y, Matsushima K, Komiyama H (2007) Creating an academic landscape of sustainability science: an analysis of the citation network. Sustain Sci 2(2):221-231

Kates, RW (2010) Readings in Sustainability Science and Technology. CID Working Paper No. 213, Kennedy School of Government, Harvard University

Kates RW (2011) What kind of a science is sustainability science? Proc Natl Acad Sci USA 108(49):19449-19450

Kates RW, Clark WC, Correll R, Hall JM, Jaeger CC, Lowe I et al (2001) Sustainability science. Science 292(5517):641-642

Hiroshi Komiyama, Takeuchi, Kazuhiko (2006) Sustainability science: building a new discipline. Sustain Sci 1(1):1-6

Komiyama, Hiroshi (2014) Beyond the limits to growth: new ideas for sustainability from Japan. Springer, Tokyo, pp 13-23

Lubchenco, J (1998) Entering the Century of the Environment: A New Social Contract for Science. Science vol 279:491-497. Available online at http://www.ask-force.org/web/Peer-Review/ Lubchenco-Entering-Century-Environment-1998.pdf. Accessed July 13, 2014

Miller TR (2012) Constructing sustainability science: emerging perspectives and research trajectories. Sustain Sci doi 10.1007/ s11625-012-0180-6. Accessed July 13, 2014

Orecchini F, Valitutti V, Vitali G (2012) Industry and academia for a transition towards sustainability: advancing sustainability science through university-business collaborations. Sustain Sci 7(Suppl 1):57-73. doi:10.1007/s11625-011-0151-3

Sala S, Farioli F, Zamagni A (2012) Progress in sustainability science: lessons learnt from current methodologies for sustainability assessment: Part I. Int J Life Cycle Assess. doi:10.1007/ s11367-012-0508-6 (Accessed July 1, 2014)

Shiroyama H, Yarime M, Matsuo M, Schroeder H, Scholz R, Ulrich AE (2012) Governance for sustainability: knowledge integration and multi-actor dimensions in risk management. Sustain Sci 7(Suppl 1):45-55. doi:10.1007/s11625-011-0155-z

Skolnikoff E (1993) The elusive transformation: science and technology and the evolution of international politics. Princeton University Press, Princeton USA

Steffen W, P Crutzen, JR McNeil (2007) The Anthropocene: Are Humans Now Overwhelming the Great Forces of Nature? Ambio vol 36(8):614-621. Available online at http://mfs.uchicago.edu/ public/institutes/2013/climate/prereadings/steffen_et_al-the_ anthropocene.pdf. (Accessed July 13, 2014).

United Nations, Millennium Development Goals Report 2011, June 2011, ISBN 978-92-1-101244-6, available at: http://www.ref world.org/docid/4e42118b2.html. Accessed 13 July 2014

Van Kerkhoff L, Lebel L (2006) Linking knowledge and action for sustainable development. NNU EWC WNCIEON EWAOUE 31:445-447 
Van der Leeuw, Sander, Wiek, Arnim, Harlow, John, Buizer, James (2012). How much time do we have? Urgency and rhetoric in sustainability science. Sustain Sci: 7 (Supplement 1:115-120). doi 10.1007/s11625-011-0153-1.

Vitousek P, Mooney H, Lubchenco J, Melillo JM (1997) Human Domination of Earth's Ecosystems. Science, New Series, Vol. 277, No. 5325: 494-499. Available online at http://webspace. pugetsound.edu/facultypages/kburnett/readings/vitousek.pdf. Accessed July 1, 2014

Wiek A, Ness B, Schweizer-Ries P, Brand F, Farioli F (2012) From complex systems thinking to transformational change: a comparative study on the epistemological and methodological challenges in sustainability science projects. Sustain Sci 7(s1): $5-24$ 